\title{
Early dialysis in a neonate with intrauterine lisinopril exposure
}

\author{
G Filler, H Wong, A S Condello, C Charbonneau, B Sinclair, T Kovesi, \\ J Hutchison
}

Arch Dis Child Fetal Neonatal Ed 2003;88:F154-F156

In general, angiotensin converting enzyme (ACE) inhibitors should be discontinued in pregnancy, as they can induce an ACE fetopathy. For the treatment of the latter, early peritoneal dialysis is recommended for in utero exposure to captopril and enalapril, although the outcome is poor. Early peritoneal dialysis has not previously been reported for lisinopril induced multiorgan failure. A case is reported in which treatment was given on postnatal day 3 . The patient recovered from oligoanuria to almost normal renal function, and heart, brain, and musculoskeletal injury was reversible. This is despite relatively poor clearance of the drug through peritoneal dialysis. Analysis of the pharmacokinetic data suggests that haemodialysis or haemofiltration would be more efficacious for removal of the drug, and these treatments should be performed if available.

$\mathrm{T}$ he use of angiotensin converting enzyme (ACE) inhibitors during pregnancy is strongly cautioned against. ${ }^{1}$ In vitro studies show that ACE inhibitors cross the human placenta. ${ }^{2}$ An intact renin-angiotensin system is a prerequisite for the normal development of the kidney, ${ }^{3}$ and it is recommended that ACE inhibitors should be stopped as soon as pregnancy is confirmed. ${ }^{4}$ Several reports describe the adverse effects of intrauterine ACE inhibitors on newborn infants. ${ }^{5-7}$ Clinical features of intrauterine exposure include oligohydramnios, pulmonary hypoplasia, neonatal renal failure, bony deformities, and an increased incidence of perinatal mortality. The postulated mechanism of insult in late pregnancy is related to fetal hypotension and a prolonged decrease in glomerular filtration secondary to the inhibition of ACE.

Although most reports on the untoward effects of ACE inhibitors during pregnancy are on the earlier ACE inhibitors, two similar reports also exist on lisinopril. ${ }^{89}$ Lisinopril is a lysine analogue of enalapril, a commonly recognized ACE inhibitor. This analogue has been shown to lack protein binding and remains unmetabolised after oral ingestion. ${ }^{10}{ }^{11}$ Elimination occurs exclusively by renal filtration of the unmetabolised drug. ${ }^{12}$

As recently as 1993, peritoneal dialysis was shown to be effective in the elimination of plasma lisinopril when instituted as late as day 10 of postnatal age. ${ }^{9}$ Peritoneal dialysis has been attempted to remove other ACE inhibitors in the past particularly during the neonatal anuric phase. ${ }^{13}$ We report our experience with peritoneal dialysis in the early neonatal period (immediately after referral on day 3 of postnatal age) in an infant with known intrauterine lisinopril exposure. This early treatment has not been previously reported and we believe that this information will be useful in similar cases.

\section{CASE REPORT}

A 3 day old infant was admitted to our paediatric intensive care unit because of respiratory distress. The history revealed intrauterine lisinopril exposure. The mother was a 31 year old gravida 4 para 1 with obesity, and had been treated for essential hypertension since the age of 17 years. Lisinopril was used in the mother for 2.5 years before the patient's presentation, during which time she had two stillbirths.

The current pregnancy was initially a twin pregnancy, with the intrauterine death of twin A occurring at 14 weeks gestation. Lisinopril was continued throughout the pregnancy. The dose was increased from 5 to $10 \mathrm{mg}$ at 7 months gestation. Oligohydramnios was first diagnosed by fetal ultrasound in twin B at 29 weeks gestation. Biophysical profile studies were scored 6 out of 8 on two separate occasions since 35 weeks with a score of 0 on both occasions for amniotic fluid level. The child was born by caesarean section because of footling breech presentation at 38 weeks gestation.

Initial Apgar scores were 9 and 9 at one and five minutes. The infant was considered mildly hypotonic but was otherwise normal. There were no concerns until after 72 hours of life, at which time the infant developed respiratory distress and was transferred to our centre for evaluation and treatment.

On examination, there were multiple congenital anomalies considered consistent with oligohydramnios and positional deformities. These included microcephaly, retrognathia, a bell shaped thorax, and fixed flexion deformities of the limbs and short fingers. The patient was hypotensive and tachycardic with an initial blood pressure of 45/20 and heart rate of 180 beats/min. Before admission, there was a history of anuria for at least 24 hours after birth.

The patient required mechanical ventilation. Peritoneal dialysis was started immediately using a percutaneously placed catheter in addition to ionotropes and antibiotic treatment for suspected sepsis. A $30 \mathrm{ml}$ volume of $1.5 \%$ dianeal was cycled continuously every hour, and blood work was monitored for response. Laboratory findings on admission showed hyponatraemia (sodium $123 \mathrm{mmol} / \mathrm{l}$ ) and raised creatinine level $(265 \mu \mathrm{mol} / \mathrm{l})$. Serum lisinopril level $(10.81 \mathrm{ng} / \mathrm{ml})$ and plasma renin activity $(>8.4 \mathrm{ng} / \mathrm{l} / \mathrm{s})$ were increased on day 3 of postnatal age before the start of peritoneal dialysis. The serum lisinopril level decreased to $2.45 \mathrm{ng} / \mathrm{ml}$ after 72 hours of dialysis (fig 1). Clearance of lisinopril by peritoneal dialysis was $0.061 \mathrm{ml} / \mathrm{min}$ over the first four hours of treatment and decreased to $0.058 \mathrm{ml} / \mathrm{min}$ after 24 hours. Urinary output increased from 0.5 to $4.9 \mathrm{ml} / \mathrm{kg} / \mathrm{hour}$, and the urinary lisinopril clearance was $1.30 \mathrm{ml} / \mathrm{min}$ after 24 hours of treatment. On day 3 of treatment the urinary output increased further to 6 $\mathrm{ml} / \mathrm{kg} / \mathrm{h}$, and the urinary lisinopril clearance rose to 3.6 $\mathrm{ml} / \mathrm{min}$ (fig 2). Dialysis was continued for a total of 72 hours.

The increased urinary output was parallelled by a fall in serum creatinine to $83 \mu \mathrm{mol} / \mathrm{l}$. Serum sodium improved to 148 $\mathrm{mmol} / \mathrm{l}$. The patient remained on ionotropes for a total of 72 hours and was extubated after 4 days of ventilatory support. Infant pulmonary function testing performed while the infant 


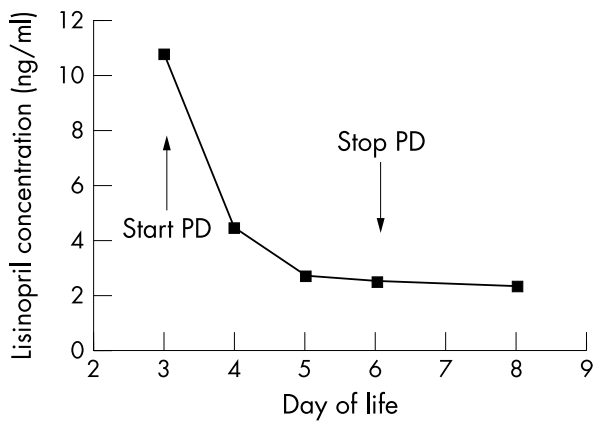

Figure 1 Serum lisinopril concentrations and their relation to peritoneal dialysis (pPD) treatment.

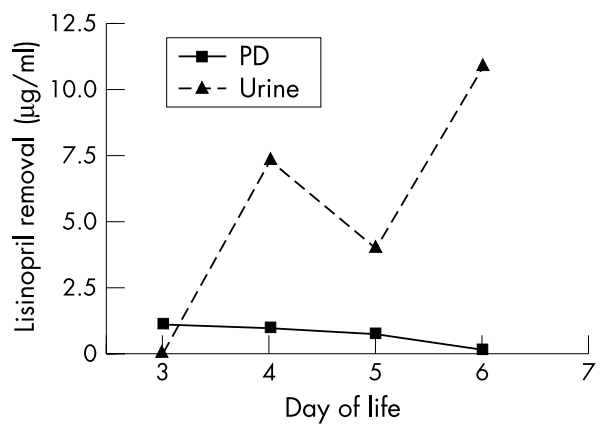

Figure 2 Amount of lisinopril removed per day by urine and peritoneal dialysis (PD).

was ventilated provided evidence of mild pulmonary hypoplasia with a dynamic compliance of $0.54 \mathrm{ml} / \mathrm{cm} \mathrm{H}_{2} \mathrm{O} / \mathrm{kg}$ (moderate reduction), a static compliance of $0.82 \mathrm{ml} / \mathrm{cm} \mathrm{H}_{2} \mathrm{O} / \mathrm{kg}$ (mild reduction), and an airway resistance of $79.3 \mathrm{~cm} \mathrm{H} \mathrm{H}_{2} \mathrm{O} / \mathrm{ml} / \mathrm{s}$ (normal).

An initial echocardiogram showed findings consistent with global myocardial insult. A renal ultrasound performed on day 5 of postnatal age showed normal sized kidneys with poor differentiation and diffuse hyperechoic areas. After dialysis the infant developed serious hypertension and was discharged on clonidine.

At 1 year of chronological age, the patient showed normal cardiac function on echocardiography. Renal ultrasound continued to show poor abnormal echogenicity with poor corticomedullary differentiation despite acceptable renal growth. The standardised glomerular filtration rate measured by technetium- $99 \mathrm{~m} N^{\alpha}$-diethylenetriaminepenta-acetic acid (DTPA) renal scan amounted to $77 \mathrm{ml} / \mathrm{min} / 1.73 \mathrm{~m}^{2}$, which compares with a normal reference range of $90-125 \mathrm{ml} / \mathrm{min} /$ $1.73 \mathrm{~m}^{2}$. Persistent hypertension continued to be a problem and was treated with clonidine. After 1 year of age the patient was converted to fosinopril to maintain a normal blood pressure. The patient was walking by 12 months and did not show any appreciable developmental delay. The patient received intense physiotherapy which resulted in normal joint motility.

\section{DISCUSSION}

Numerous case series and various case reports have already documented the disastrous effects of intrauterine exposure to ACE inhibitors..$^{3-5}$ Dialysis has also been suggested in a few reports as a means of encouraging elimination of the offending agent especially during the anuric phase. ${ }^{913}$

Rosa et $a l^{13}$ published a series of seven case reports on patients who were exposed to either enalapril or captopril in utero. Six developed hypotension, and all seven developed neonatal oliguria/anuria secondary to ACE inhibitor exposure. Six of the seven patients in that series received dialysis. Dialysis was instituted on day 2 in one patient, day 3 in three patients, and on day 5 and 19, respectively. Two of the seven infants recovered normal kidney function, and these two had been dialysed on day 2 and 3 respectively. Two infants died (either no dialysis or dialysis instituted on day 19), and the remaining three had residual kidney impairment. ${ }^{11}$

Bhatt-Mehta and Deluga" published a single case report in which continuous peritoneal dialysis was started in the late neonatal period to eliminate lisinopril. This report showed an initial serum lisinopril level of $7.0 \mathrm{ng} / \mathrm{ml}$ on day 12 of postnatal age and a low ACE activity level. After dialysis was started, lisinopril levels fell to $0.7 \mathrm{ng} / \mathrm{ml}$ by day 38 postnatal age. ${ }^{10}$ This patient never recovered renal function and received a renal transplant at 22 months of age. Our patient had an initial lisinopril concentration of $10.81 \mathrm{ng} / \mathrm{ml}$, and has a glomerular filtration rate at 1 year of age that is almost normal.

Similar to the recommendations on enalapril and captopril in the literature, we instituted early peritoneal dialysis for the treatment of intrauterine lisinopril exposure. Early use of dialysis in patients with intrauterine lisinopril exposure has not been reported previously. Serum lisinopril levels fell from $10.81 \mathrm{ng} / \mathrm{ml}$ to $2.45 \mathrm{ng} / \mathrm{ml}$ after 72 hours of dialysis. There was also a corresponding resolution of hypotension and improvement in urine output, suggesting a direct contribution to the clinical recovery. Nonetheless, the actual drug clearance by peritoneal dialysis was low, although the serum concentration of lisinopril fell from 10.81 to $4.47 \mathrm{ng} / \mathrm{ml}$. The actual concentrations of lisinopril in the peritoneal dialysis fluid were comparable to those in the case reported by Bhatt-Mehta and Deluga. ${ }^{9}$ However, their patient failed to show an appreciable decrease in serum concentration over the first four days of treatment $(7.0 \mathrm{ng} / \mathrm{ml}$ before dialysis and $6.3 \mathrm{ng} / \mathrm{ml}$ on day 4 of treatment), again pointing to poor clearance of the drug through peritoneal dialysis. In our patient the urinary clearance exceeded that by peritoneal dialysis after as little as 24 hours of treatment. It remains unclear whether the improvement in our patient was not in fact predominantly influenced by the recovery from presumed acute tubular necrosis with the normalisation of the blood pressure. However, the prognosis appears to be dependent on the early initiation of dialysis. As the plasma protein binding of lisinopril is negligible, haemodialysis would be the treatment of choice. It appears to be just as important to treat the hypotension to maximise the likelihood of recovery from the presumed acute tubular necrosis. In the event of another case of in utero lisinopril exposure with multiorgan failure, we would recommend acute haemodialysis or continuous venovenous haemodiafiltration to rapidly reduce the serum concentration, provided that experienced personel are available. Continuous venovenous haemodiafiltration would be safer as these patients would have hypotension. In the absence of these modalities, early peritoneal dialysis should be implemented, using higher dwell volumes than usual to maximise clearance of the drug.

\section{ACKNOWLEDGEMENTS}

We thank Merck Laboratories for their prompt and non-bureaucratic assistance and the free measurements of the lisinopril concentrations. The measurements were performed by Dr E Hand, Merck Laboratories, Clinical Drug Metabolism, West Point, PA 19486, USA.

\section{Authors' affiliations}

G Filler, H Wong, A S Condello, C Charbonneau, B Sinclair,

T Kovesi, J Hutchinson, Department of Paediatrics, Children's Hospital of Eastern Ontario, 401 Smyth Road, Ottawa, ON K2H 7M9, Canada

Correspondence to: Professor Filler, Department of Paediatrics, Division of Nephrology, Children's Hospital of Eastern Ontario, University of Ottawa, 401 Smyth Road, Ottawa, ON K1H 8L1, Canada;

filler@cheo.on.ca

Accepted 5 August 2002 


\section{REFERENCES}

1 Food and Drug Administration. Warnings on the use of ACE inhibitors in the second and third trimester of pregnancy. JAMA 1992:267:2445.

2 Reisenberger K, Egarter C, Sternberger B. Placental passage of angiotensin-converting enzyme inhibitors. Am J Obstet Gynecol 1996; 174:1450-5.

3 Guron G, Friberg P. An intact renin-angiotensin system is a prerequisite for normal renal development. J Hypertens 2000:18:123-37.

4 Buttar HS. An overview of the influence of ACE inhibitors on fetal-placental circulation and perinatal development. Mol Cell Biochem 1997; 176:61-71.

5 Shotan A, Widerhorn J, Hurst A. Risk of angiotensin- converting enzyme inhibition during pregnancy: experimental and clinical evidence potential mechanisms, and recommendations for use. Am J Med 1994;96:451-6

6 Schubiger G, Flury G. Enalapril for pregnancy-induced hypertension: acute renal failure in a neonate. Ann Intern Med 1988:108:215-16.
7 Cunniff C, Jones KL, Phillipson J. Oligohydramnios sequence and renal tubular malformation associated with maternal enalapril use. Am J Obstet Gynecol 1990;162:187-9.

8 Tomlinson AJ, Campbell J, Walker JJ, et al. Malignant primary hypertension in pregnancy treated with lisinopril. Ann Pharmacother 2000;34:180-2.

9 Bhatt-Mehta V, Deluga KS. Fetal exposure to lisinopril: neonatal manifestations and management. Pharmacotherapy 1993;13:515-18.

10 Gomez H, Cirillo V, Moncloa F. The Clinical pharmacology of lisinopril. J Cardiovasc Pharmacol 1987;9(suppl 3):S27-34

$11 \mathrm{Ulm}$ EH, Hichens M, Gomez HJ. Enalapril maleate and a lysine analogue (MK-521): disposition in man. Br J Clin Pharmacol 1982; 14:357-62.

12 Beerman B. Pharmokinetics of lisinopril. Am J Med 1988;85(suppl 3B):25-30.

13 Rosa F, Bosco L, Fossum C. Neonatal anuria with maternal angiotensinconverting enzyme inhibition. Obstet Gynecol 1989;74:371-4.

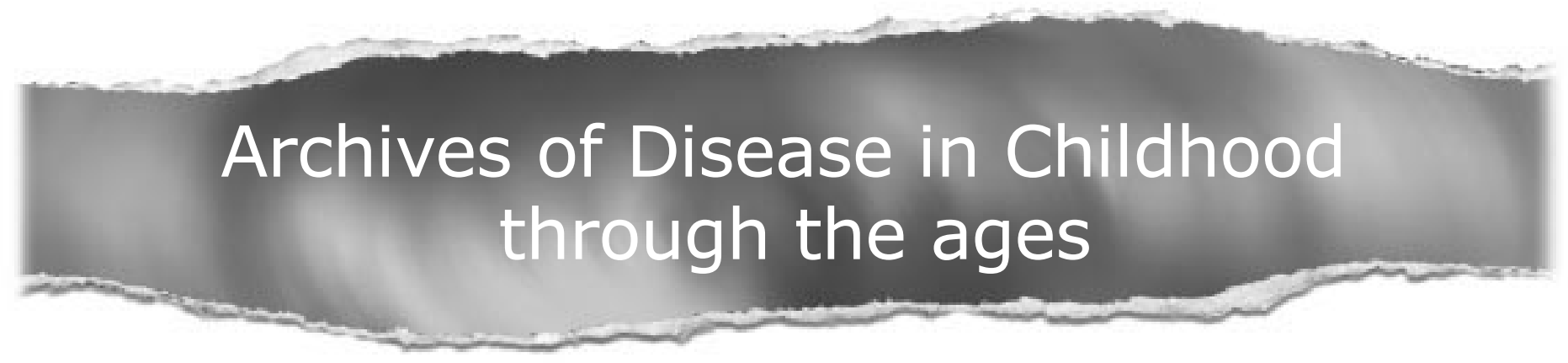

Browse the Archive

Archives of Disease in Childhood online has an archive of content dating back to 1973.

Full text from 1997; abstracts from 1975; table of contents from 1973

www.archdischild.com 